DOI:10.17951/h.2019.53.1.19-27

\begin{tabular}{lcc}
\hline & A N N A L E S \\
UNIVERSITATIS MARIAE CURIE-SKŁODOWSKA \\
LUBLIN - POLONIA \\
SOL. LIII, 1 & SECTIO H \\
\hline
\end{tabular}

\author{
ILONA BONDOS \\ ilona.bondos@poczta.umcs.lublin.pl \\ Maria Curie-Skłodowska University, Faculty of Economics, \\ pl. Marii Curie-Skłodowskiej 5, 20-031 Lublin, Poland \\ ORCID ID: https://orcid.org/0000-0002-9759-8517
}

\title{
Consumer experience in phone communication in the service purchasing process
}

\author{
Keywords: service buying process; customer journey; phone channel; consumer-initiated communi- \\ cations; CIC; multichanneling \\ JEL: M31; M21; L81
}

How to quote this paper: Bondos, I. (2019). Consumer experience in phone communication in the service purchasing process. Annales Universitatis Mariae Curie-Skłodowska, sectio H-Oeconomia, Vol. 53, No. 1.

\footnotetext{
Abstract

Theoretical background: Consumers today are presented with a myriad of opportunities through which the purchase process can be realized (Yrjölä et al., 2018, p. 1133). The customer journey can be defined as a buyer's behaviour in a multi (omni) environment with the goal of finalizing purchase transactions and acquiring positive (seamless, holistic) customer experiences. Researchers look at a service buying process as the customer value-adding journey (Saghiri et al., 2017; Wilding, 2003) and its prime objective is to deliver a positive customer experience at each of stage of the buying process. According to media richness theory (MRT), voice-based communication is ranked higher than text-based communication along the media richness continuum (Daft \& Lengel, 1984), however, some additional findings have been also revealed. Taking into account the traditional continuum of media richness, phone communications is perceived as rich in information; only face to face contact is seen as richer (Suh, 1999). As stated in Rhee (2010), customer-initiated communications via phone channel is preferred when the consumer faces an extended problem-solving (high perceived risk/low familiarity) situation. Whereas, in the case of routine problem-solving, the situation online channel is preferred. However, some relevant research on marketing channel richness has been proposed by Kwak (2012) as well as Lipowski and Bondos (2018). According
} 
to this research stream, the medium itself does not necessarily determine its perceived media richness. The key factor is user's familiarity with a particular marketing channel and his/her ability to use its communicational potential.

Purpose of the article: The present study attempts to provide evidence about the potential of the phone channel as the channel of contact with the service provider through the entire service buying process, including four stages: pre-purchase, purchase, post-purchase and resignation from service. The main goal of the study is to identify the level of customers' experience/knowledge of using the phone channel by the three consumer generations (Baby Boomers, $\mathrm{X}$ and $\mathrm{Y}$ ).

Research methods: The survey study was conducted in September-November 2015 on a group of 1,103 respondents (Polish adult consumers) including 357 (BB), 390 (X) and $356(\mathrm{Y})$. The research sample was determined by the quota-random method; the CAPI (computer-assisted personal interview) method was used with a standardized questionnaire. In order to verify the research hypothesis, MANOVA was used with data on three customer generations.

Main findings: The BB generation possesses the least experience in phone communication in the service buying process. Next is the $\mathrm{X}$ generation with more phone communication experience than BB but less than the $\mathrm{Y}$ generation. At each stage in the service purchasing process, the $\mathrm{Y}$ generation is the most knowledgeable in the area of phone communication. In general, there is a visible downward trend of the own experience level along with further stages in the service purchasing process. In terms of phone communication, the most mysterious for customers is the last phase.

\section{Introduction}

Consumers today are presented with a myriad of opportunities through which the purchase process can be realized (Yrjölä et al., 2018, p. 1133). Changes in consumer behaviour, as well as new technologies, have fostered the transition from multichannel to omnichannel marketing. Much research effort has been devoted to examining the differences between the omnichannel strategy and multichannel strategy (e.g. Berman \& Thelen, 2018; Simone \& Sabbadin, 2018; Verhoef et al., 2015; Yrjölä et al., 2018). Researchers pay attention to the so-called "touch and feel" factor that creates one of the dimensions of the distinctive advantages of offline retailers over online retailers (Deshwal, 2016, p. 941). Due to changes in the marketing landscape, the customer experience issue is gaining in importance (Homburg et al., 2017, p. 377). As indicated by Verhoef et al. (2015, p. 3), the great challenge for the service provider is to provide the customer with a click and brick experience without a separation of each of marketing channels. The essence of omnichanneling gives customers freedom to choose any marketing channel at a particular stage in the purchasing process in order to maximize his or her shopping convenience and to enjoy a seamless shopping experience (Brynjolfsson et al., 2013). With that in mind, there should be wider knowledge of the behavioural intention to use each of the available marketing channels throughout the entire service buying process. In an omnichannel environment, Mosquera et al. (2018, p. 67) emphasise the meaning of not only the retailer's technologies but also the personal devices that customers use. The present study attempts to provide evidence about the potential of the phone channel as the channel of contact with the service provider through the entire service 
buying process. The main goal of the study is to identify the level of use the phone channel currently and the intention to use it in the future by the three consumer generations (Baby Boomers, $\mathrm{X}$ and $\mathrm{Y}$ ).

\section{Literature review}

The customer journey can be defined as a buyer's behaviour in a multi (omni) environment with the goal of finalizing purchase transactions and acquiring positive (seamless, holistic) customer experiences. Researchers look at a service buying process as the customer value-adding journey (Saghiri et al., 2017; Wilding, 2003) and its prime objective is to deliver a positive customer experience at each of stages of the buying process. By analogy to what has been stated in Saghiri et al. (2017, p. 55) in reference to product return, different ways to end the cooperation with the service supplier may have different kinds/levels of value for the customer, depending on their availability, convenience, cost or speed. Jüttner et al. (2013, p. 746) indicate several episodes that create the total service experience in the case of a particular service. One of these episodes is payment and good-bye (restaurant case) and check-out and good-bye (hotel case). It seems clear that retailers should not attempt to build relationships with all their customers, as they cannot all be served profitably, nor would they all want to form relationships with the retailer's brand (Moster et al., 2016). This statement puts emphasis on the fact that some of the current clients will end their relations with the service brand, however, this does not absolve the service provider from the obligation to ensure that marketing efforts create positive customer experiences until the last moment of contact with the brand. Until the very end of the relationship with the service supplier, customers deserve a positive experience. Lipowski (2018) finds that the service resignation stage as well as all previous stages in the service buying process can be a source of value for customer. The service literature currently includes multiple characterizations of the customer experience, partially due to the experience concept's complexity (Lipkin, 2016, p. 680). De Haan et al. (2018, p. 16) note the potential of tracking customers across devices used by them in the purchase process. Holmes et al. (2014, p. 36) pay attention to the different intensity of using mobile phones in the purchase process, however, in their analysis, the service resignation (or product return) stage has not been included. According to them, there is a higher use of the mobile phone in the information search and consideration of alternatives phases than in the purchase transaction.

Numerous works have studied marketing communications (Kleinlercher et al., 2018; Manser et al., 2017) and researchers examine the communications process as the tool for differentiating and creating competitive advantage for itself and its products as well being a valued factor in building relations with customers and an integral part of the service experience from the customers' perspective (Madden \& Perry, 2003, p. 114). There is no doubt that changes in the field of information and 
communications technologies promote the growth of the importance of the customer-initiated communications (CIC). In the light of the literature, CIC is perceived as the valuable source of information about consumers' thoughts and problems. Therefore, CIC is one of the important elements of the process of customer management (Bowman \& Narayandas, 2001). It seems that the current decision of the style of ending the relationship with customers can be a potential source of value in the future. Reacquired customers' experiences with the firm clearly distinguishes them from newly acquired customers (second lifetime vs. first lifetime) (Kumar et al., 2018, p. 209). Adebiyi et al. (2016, p. 13) note that in order to satisfy customers, social exchange theory must hold. According to this theory, human behaviour or social interaction is an exchange of rewards and costs, and customers as well as service providers would not continue a relationship in the long-run if such reciprocity was violated.

According to media richness theory (MRT), voice-based communication is ranked higher than text-based communication along the media richness continuum (Daft \& Lengel, 1984), however, some additional findings have been also exposed. Taking into account the traditional continuum of media richness, phone communication is perceived as rich in information, and only face to face contact is seen as richer (Suh, 1999). As is stated in Rhee (2010), customer-initiated communications via phone channel is preferred when the consumer faces an extended problem-solving (high perceived risk/low familiarity) situation. Whereas, in the case of a routine problem-solving situation, the online channel is preferred. However, some relevant research on marketing channel richness has been proposed by Kwak (2012) as well as Lipowski and Bondos (2018). According to this research stream, the medium itself does not necessarily determine its perceived media richness. The key factor is user's familiarity with a particular marketing channel and his/her ability to use its communicational potential. Consequently, a current phone channel that is more smartphone channel than conventional phone channel seems to obtain an impressive potential in media richness and in solving communicational tasks.

\section{Research methodology}

The study was conducted in September-November 2015 on a group of 1,103 respondents (Polish adult consumers) including 357 from a Baby Boomer generation (BB), 390 from the $\mathrm{X}$ generation and 356 from the $\mathrm{Y}$ generation. The research sample was determined by the quota-random method - quotas due to age and gender and the nature of the place of residence (city provincial, city other than provincial, village) - and the structure of the sample was preserved at the regional level.

The CAPI (computer-assisted personal interview) method was used with a standardized questionnaire. Questions about the intention to use the phone channel and the customer's own experience with using the phone channel at each of stage in the 
service buying process were scaled using a seven-point Likert-type scale anchored at 1 - "strongly disagree", 4 - "neutral", and 7 - "strongly agree". Two latent variables were considered in reference to each of the four stages in the service buying process. Items defining the customer own experience (E) were adapted from: Maity et al. (2012): E1: I have a lot of experience with phone shopping. E2: With respect to phone shopping, I feel competent.

The following two research hypotheses have been formulated:

H1: At a particular stage in the service buying process, there is a difference in consumer generations' own experience in the use of the phone channel.

$\mathrm{H} 2$ : Within a specific consumer generation, the consumer's experience in phone communication in the service buying process varies depending on the stage of this process.

\section{Results}

In order to verify the research hypotheses, MANOVA was used with data on three customer generations (BB, X, Y). Figure $1^{1}$ shows that the BB generation possesses the least experience in phone communication in the service buying process. The next is the $\mathrm{X}$ generation with more phone communication experience than $\mathrm{BB}$ but less than the $\mathrm{Y}$ generation. At each stage in the service purchasing process, the $\mathrm{Y}$ generation is the most knowledgeable in the area of phone communication. Analysing the own experience of consumers representing each of the three generations, one can also identify some interesting differences. The BB generation shows the most experience in using the phone channel at the pre-purchase stage. Their experience at the purchase stage is less and does not differ from the level of experience at the post-purchase stage. However, the experience at the resignation stage is greater than at the previous stage (after-sales service); at the same time, it does not differ significantly from the competences from the purchase stage. In terms of consumer experience, the two younger generations are similar. Both generations $\mathrm{X}$ and $\mathrm{Y}$ indicate their greater experience in phone communication at the stage of information seeking. The next two stages are rated by these generations as an area less well-known for phone communication. Finally, they have the least experience in the field of using the phone channel with the purpose of a service resignation.

1 Pairwise comparisons are based on estimated marginal means pointed such differences. However, due to the volume requirements of the text, tables connected with the graphs have not been placed in the article. 
Pobrane z czasopisma Annales $\mathrm{H}$ - Oeconomia http://oeconomia.annales.umcs.pl Data: 26/04/2023 09:08:57

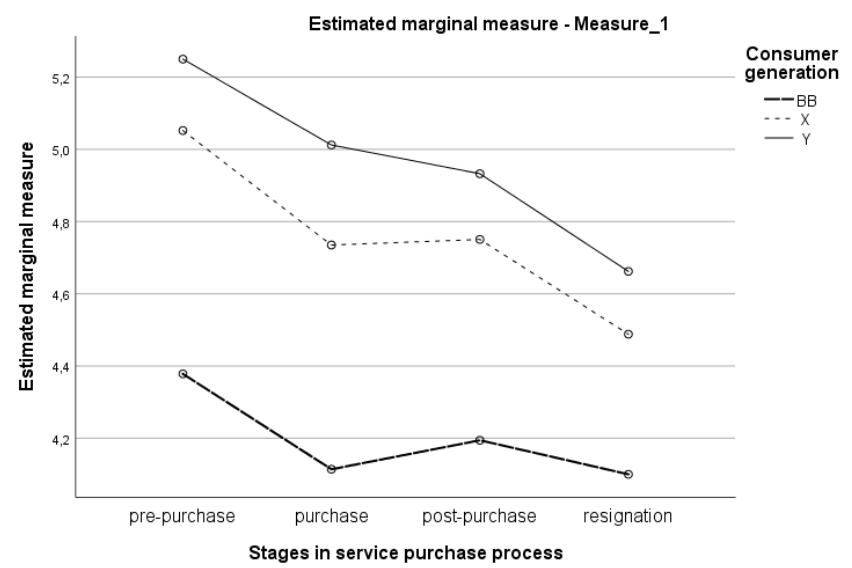

Figure 1. Customer own experience in using the phone channel in service buying process Source: Author's own study.

Figure 2 refers to the intention to use the phone channel. Using the MANOVA, a statistically significantly lower intention to use the phone channel by the BB generation than generations $\mathrm{X}$ and $\mathrm{Y}$ has been identified. Furthermore, the two younger generations show a similar intention to use the phone channel in the service buying process (Figure 2). The comparison of both Figures (1 and 2) is the basis for formulating certain conclusions. The BB generation seems to have no gap between its behavioural intention and current experience in phone communication in the service buying process, while both younger generations seem to have such a gap in the case of stages following the information searching phase. However, it should be

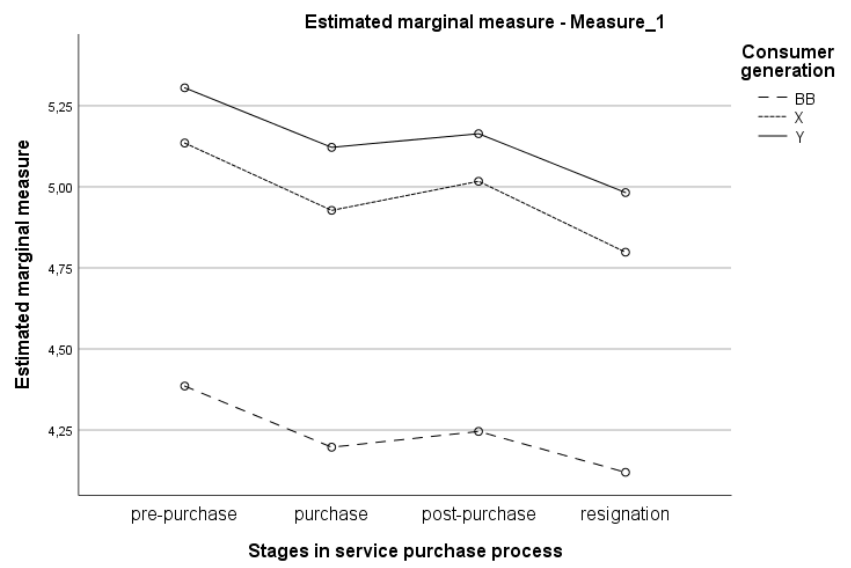

Figure 2. Intention to use the phone channel in the four-stages service buying process 
clearly stressed that an unambiguous indication of the above requires an additional analysis for each generation of consumers. If such observations were confirmed, it would be empirical proof of the phone channel development potential in the service purchase process. Thus, supporting the argument for using phone communication in the multichannel communication with service buyers.

\section{Discussions}

The positive verification of the research hypotheses indicates two important issues. First, at each four stages of service purchasing process, with the age of the consumer decrease his/her competences in the area of phone communication with the service provider. Second, generations of consumers are not internally consistent in terms of their competence in using the phone channel at particular stages of the purchase process. In the case of all consumer generations, there is a visible downward trend of the own experience level along with further stages in the service purchasing process. Consumers have the least knowledge of the phone channel at the stage of resignation from service; the older the generation, the lower the level of it. Such a differentiation of experience in phone communication in the service buying process should be seen by service providers as a vital issue determining behavioural intention. General lack of competence and experience among service clients can be one of the main barriers in encouraging customers to use phone communication in the service buying process. It can be assumed that the less knowledge the consumer has about a particular option, the less their initiative to expand their knowledge and experience in this area. The presented findings can aid retail service providers in more effectively designing and managing the service buying process, with special attention devoted to the more "unknown" stages for customers. In terms of phone communication, the most mysterious is the last phase. However, taking into account data on intention to use the phone channel, service providers should aim to enhance their younger customers' general shopping experience via phone communication. The main challenge concerns the effective conviction for phone communication. Therefore, the next move belongs to the service providers - what will their inclination be to include the phone channel in the procedure of the efficient resignation of the service by the client? Doing so would provide managers with the opportunity to better (re)target and serve customers in the last stage of their value-adding journey.

Although the results of this study have useful implications, some limitations must be considered. First, the current legal restrictions regarding the conditions for declining the service need to be acknowledged. So far, in Poland, a written form is required to recognize the validity of the resignation from the service delivery. For this reason, the final end of cooperation with service supplier through the pure phone channel (phone conversation) is not yet possible. However, the research findings are still worth analysing and implementing - at least some part of the whole service resig- 
nation process can be done via the phone channel. The perceived time and monetary matters are equivalently important to service customers (Bondos, 2018); thus, the option of a full or at least partial service resignation process via the phone channel may have the potential of competitive advantage for the service supplier. Another solution is to complete the service resignation process with digital communication smartphones give service suppliers many opportunities to reinforce consumer loyalty, enhance the service and generate positive eWOM. A second limitation refers to the lack of a direct comparison of the behavioural intention with the customer's own experience. Addressing such a gap would give a direct indication of the potential of the phone channel in the service purchasing process.

Acknowledgement: Source of research: National Science Centre, Poland, grant No. 2014/13/B/HS4/01612.

\section{References}

Adebiyi, S.O., Oyatoye, E.O., \& Amole, B.B. (2016). Improved customer churn and retention decision management using operations research approach. Emerging Markets Journal, 6(2).

DOI: 10.5195/emaj.2016.101.

Berman, B., \& Thelen, S. (2018). Planning and implementing an effective omnichannel marketing program. International Journal of Retail \& Distribution Management, 46(7).

DOI: https://doi.org/10.1108/IJRDM-08-2016-0131.

Bondos, I. (2018). When Secondary Cost Becomes an Element of the Primary Cost - Perception of the Importance of Service Purchase Costs. 32nd IBIMA Conference Proceedings, pp. 4256-4262.

Bowman, D., \& Narayandas, D. (2001). Managing customer-initiated contacts with manufacturers: The impact on share of category requirements and word-of-mouth behavior. Journal of Marketing Research, 38(3).

Brynjolfsson, E., Hu, Y.J., \& Rahman, M.S. (2013). Competing in the age of omni-channel retailing. MIT Sloan Management Review, 54(4).

Daft, R.L., \& Lengel, R.H. (1984). Information richness: A new approach to managerial behavior and organization design. Research in Organizational Behavior, 6.

Deshwal, P. (2016). Customer experience quality and demographic variables (age, gender, education level and family income) in retail stores. International Journal of Retail \& Distribution Management, 44(9). DOI: https://doi.org/10.1108/IJRDM-03-2016-0031.

De Haan, E., Kannan, P.K., Verhoef, P.C., \& Wiesel, T. (2018). Device switching in online purchasing: examining the strategic contingencies. Journal of Marketing, 82. DOI: https://doi.org/10.1509/jm.17.0113.

Holmes, A., Byrne, A., \& Rowley, J. (2014). Mobile shopping behaviour: Insights into attitudes, shopping process involvement and location. International Journal of Retail and Distribution Management, 42(1). DOI: https://doi.org/10.1108/IJRDM-10-2012-0096.

Homburg, C., Jozić, D., \& Kuehnl, C. (2017). Customer experience management: Toward implementing an evolving marketing concept. Journal of the Academy of Marketing Science, 45(3).

DOI: https://doi.org/10.1007/s11747-015-0460-7.

Jüttner, U., Schaffner, D., Windler, K., \& Maklan, S. (2013). Customer service experiences: Developing and applying a sequential incident laddering technique. European Journal of Marketing, 47(5/6). DOI: https://doi.org/10.1108/03090561311306769. 
Kleinlercher, K., Emrich, O., Herhausen, D., Verhoef, P.C., \& Rudolph, T. (2018). Websites as information hubs: How informational channel integration and shopping benefit density interact in steering customers to the physical store. Journal of the Association for Consumer Research, 3(3).

DOI: http://dx.doi.org/10.1086/698415.

Kumar, V., Leszkiewicz, A., \& Herbst, A. (2018). Are you back for good or still shopping around? Investigating customers' repeat churn behavior. Journal of Marketing Research, 55(2).

DOI: https://doi.org/10.1509/jmr.16.0623.

Kwak, H. (2012). Self-disclosure in online media. An active audience perspective. International Journal of Advertising, 31(3). DOI: https://doi.org/10.2501/IJA-31-3-485-510.

Lipkin, M. (2016). Customer experience formation in today's service landscape. Journal of Service Management, 27(5). DOI: https://doi.org/10.1108/JOSM-06-2015-0180.

Lipowski, M. (2018). Customer Churn as a Purchase Journey Stage. 32nd IBIMA Conference Proceedings, pp. 5270-5278.

Lipowski, M., \& Bondos, I. (2018). The influence of perceived media richness of marketing channels on online channel usage: Intergenerational differences. Baltic Journal of Management, 13(2).

DOI: https://doi.org/10.1108/BJM-04-2017-0127.

Madden, K.M., \& Perry, Ch. (2003). How do customers of a financial services institution judge its communications?. Journal Of Marketing Communications, 9.

Maity, M., Hsu, M.K., \& Pelton, L.E. (2012). Consumers' online information search: Gen Yers' finding needles in the internet haystack. Journal of Marketing Channels, 19(1).

DOI: https://doi.org/10.1080/1046669X.2012.635370.

Manser, P.E., Peltier, J.W., \& Barger, V.A. (2017). Omni-channel marketing. integrated marketing communications and consumer engagement: A research agenda. Journal of Research in Interactive Marketing, 11(2). DOI: https://doi.org/10.1108/JRIM-08-2016-0091.

Moster, P.G., Petzer, D.J., \& Weideman, A. (2016). The interrelationships between customer satisfaction. brand loyalty and relationship intentions of Generation Y consumers towards smart phone brands. South African Journal of Business Management, 47(3). DOI: 10.4102/sajbm.v47i3.65.

Mosquera, A., Olarte-Pascual, Ch., Juaneda Ayensa, E., \& Sierra Murillo, Y. (2018). The role of technology in an omnichannel physical store: Assessing the moderating effect of gender. Spanish Journal of Marketing - ESIC, 22(1). DOI: https://doi.org/10.1108/SJME-03-2018-008.

Rhee, E. (2010). Multi-channel management in direct marketing retailing: Traditional call center versus Internet channel. Journal of Database Marketing \& Customer Strategy Management, 17(2).

Saghiri, S., Wilding, R., Mena, C., \& Bourlakis, M. (2017). Toward a three-dimensional framework for omni-channel. Journal of Business Research, 77. DOI: https://doi.org/10.1016/j.jbusres.2017.03.025.

Simone, A., \& Sabbadin, E. (2017). The new paradigm of the omnichannel retailing: Key drivers. new challenges and potential outcomes resulting from the adoption of an omnichannel approach. International Journal of Business and Management, 13(1). DOI: https://doi.org/10.5539/ijbm.v13n1p85.

Suh, K.S. (1999). Impact of communication medium on task performance and satisfaction: An examination of media-richness theory. Information and Management, 35(5).

DOI: https://doi.org/10.1016/S0378-7206(98)00097-4.

Verhoef, P.C., Kannan, P.K., \& Inman, J.J. (2015). From multi-channel retailing to omnichannel retailing: Introduction to the special issue on multi-channel retailing. Journal of Retailing, 91(2).

DOI: https://doi.org/10.1016/j.jretai.2015.02.005.

Wilding, R. (2003). The 3Ts of highly effective supply chains. Supply Chain Practice, 5(3).

Yrjölä, M., Saarijärvi, H., \& Nummela, H. (2018). The value propositions of multi- cross- and omni-channel retailing. International Journal of Retail \& Distribution Management, 46(11/12).

DOI: https://doi.org/10.1108/IJRDM-08-2017-0167. 